\title{
Synthesis and Morphological Transformation of Conjugated Amphiphilic Diblock Copolymers in Mixed Solvents
}

\author{
Yang-Yen Yu, ${ }^{1,2,3}$ Chung-Yi Hsu, ${ }^{1}$ and Guo-You Li ${ }^{1}$ \\ ${ }^{1}$ Department of Materials Engineering, Ming Chi University of Technology, 84 Gungjuan Road, Taishan District, \\ New Taipei City 24301, Taiwan \\ ${ }^{2}$ Center for Thin Film Technologies and Applications, Ming Chi University of Technology, 84 Gungjuan Road, \\ Taishan, New Taipei City 243, Taiwan \\ ${ }^{3}$ Battery Research Center of Green Energy, Ming Chi University of Technology, 84 Gungjuan Road, Taishan District, \\ New Taipei City 24301, Taiwan
}

Correspondence should be addressed to Yang-Yen Yu; yyyu@mail.mcut.edu.tw

Received 9 November 2012; Accepted 29 December 2012

Academic Editor: Gong Ru Lin

Copyright (c) 2013 Yang-Yen Yu et al. This is an open access article distributed under the Creative Commons Attribution License, which permits unrestricted use, distribution, and reproduction in any medium, provided the original work is properly cited.

\begin{abstract}
The synthesis, morphological transformation, and photophysical properties of a rod-coil block copolymer, poly[2,7-(9,9-dihexylfluorene)]-block-poly(2-vinylpyridine) (PF-b-P2VP), with P2VP coils of various lengths in a mixed methanol/tetrahydrofuran (MeOH/THF) solvent are reported. Various morphological structures of PF-b-P2VP aggregates, including spheres, short wormlike structures, long cylinders, and large compound micelles (LCMs), were observed after varying the coil length of PF-b-P2VP and the selectivity of mixed solvents. These aggregated structures demonstrated considerable variation with regard to optical absorption, fluorescence, and the PL quantum yield of rod-coil copolymers. The degree of hypsochromic spectral shift was enhanced as the length of P2VP coils and the content of poor solvent increased. This study reveals the influence of coil length and selectivity of solvents on the morphology and the optical characteristics of rod-coil amphiphilic copolymers.
\end{abstract}

\section{Introduction}

The self-assembly of amphiphilic block copolymers (ABCs) is considered a promising approach to synthesize nanostructured or hierarchical materials with novel morphological and physical properties for advanced applications in areas such as electronics, optoelectronics, biotechnology, and environmental technology [1-13]. The morphology of amphiphilic block copolymers can be manipulated using different driving forces, including relative block length, block polarity, volume fraction, and temperature [14-16]. Recently, amphiphilic rod-coil diblock copolymers $[17,18]$ have attracted considerable attention, as they produce novel self-organizing structures in the form of stiff rod-like segments, such as helical [19] and $\pi$-conjugation polymers [20-25]. In the past 5 years, a great number of new $\pi$-conjugated polymers have been synthesized and used in various biological applications such as sensing and imaging agents. These studies have focused on highly sensitive diagnosis of pathogenic microorganisms and tumor cells and detection of diseaserelated biomarkers. Beyond sensing, fluorescence imaging in vitro has also been successfully achieved. Besides, these materials have also attracted much attention for biomedical applications, such as monitoring drug delivery and release, gene delivery, drug screening, and anti-microorganism and anticancer therapies [26-28].

Rod-coil block copolymers containing $\pi$-conjugation chains are of particular importance because conjugated homopolymers are among the most promising candidates for low-cost, large-area, flexible organic electronics [29]. The high immiscibility and stiffness asymmetry between rigid conjugated rods and flexible coil segments significantly influence the molecular packing of polymers, leading to self-organized aggregation. The aggregation of rod-like conjugated chains enables the production of a wide variety of 
supramolecular structures at nanoscale dimensions, including lamellar, spherical, cylindrical, vesicular, and worm-like structures that further influence electronic and photophysical properties $[17,18]$. Polyfluorene (PF) and its derivatives have been widely used for polymer light-emitting diodes, owing to their high fluorescence quantum yield and good charge transport ability [30-33]. Although PF is a promising material for light-emitting diodes, PF chains tend to stack cofacially and form excimers due to intermolecular $\pi-\pi$ interaction, which results in nonradiative decay and a subsequent reduction in the performance of devices. A diblock architecture is one possible solution to lower the intermolecular interaction in PF and suppress the formation of excimers [34]. Moreover, the photophysical properties are possibly influenced strongly by variations in the morphology of rod-coil copolymers. Rodcoil block copolymers with fluorene-based segments have been reported by several groups [35-37]. The importance of the morphological transformation of rod-coil poly[2,7-(9,9dihexylfluorene)]-block-poly(2-vinylpyridine) (PF-b-P2VP) via selective solvents on optical characteristics has been demonstrated [22]. Diverse morphological and optical properties can be induced in the aggregate by changing the $\mathrm{MeOH} / \mathrm{THF}$ ratio. However, the means by which the length of coil segments and solvent quality influence the morphology of PF-b-P2VP have not yet been fully explored.

This study demonstrates the synthesis, morphology, and photophysical properties of amphiphilic $\mathrm{PF}_{m}-\mathrm{b}-\mathrm{P} 2 \mathrm{VP}_{n}$ at a fixed rod length $(m=10)$ with three different coil lengths $(n=35,55,75)$. The chemical structure of the studied polymers and the synthetic scheme for the PF-b-P2VP block copolymer are shown in Scheme 1. By varying the selectivity of the solvents and the annealing temperature, polymers with various aggregation morphologies were induced. This paper reveals the influence of the ratio of poor/good solvents on the morphological and photophysical properties of these diblock copolymers with various coil lengths as well as the spectral stability of PF-b-P2VP. Finally, transmission electron microscopy (TEM), atomic force microscopy (AFM), UVvis optical absorption, and photoluminescence (PL) spectroscopy were employed to investigate the correlation between optical characterization and morphology.

\section{Experimental}

2.1. Materials. 9,9-dihexyl-2-7-dibromofluorene (F, Aldrich, 97\%), 2-Vinylpyridine (2VP, Acros, 97\%), copper(I) bromide (CuBr, Aldrich, 99.999\%), anhydrous tetrahydrofuran (THF, Echo), $\quad N, N, N^{\prime}, N^{\prime}, N^{\prime \prime}$-pentamethyldiethylenetriamine (PMDETA, Aldrich, 99\%), anhydrous methyl alcohol (MeOH, Mallinckrodt), n-hexane (Tedia, 95\%), Aluminium oxide (50-200 micron, Acros), and chloroform-d (99.8 atm\% $\mathrm{D}$, Aldrich) were used as received to prepare the PF-b-P2VP copolymers.

2.2. Synthesis of PF-b-P2VP Copolymers and Preparation of PF-b-P2VP Aggregates in Mixed Solvents. First, $\alpha-(4-$ hydroxymethyl phenyl)- $\omega$-bromo-poly[2,7-(9,9-dihexyl-fluorene)] was synthesized according to the literature [38]. 2bromo-7-bromohydroxide-9,9-dioctylfluorene was prepared by boronation of 9,9-dihexyl-2,7-dibromofluorene with tri-isopropyl borate at $-78^{\circ} \mathrm{C}$. The polymerization of the prepared product using a modified Suzuki coupling protocol followed by end capping with bromobenzene yielded $\alpha$-bromo- $\omega$-phenyl-poly(9,9-dioctylfluorene). Then, a second Suzuki reaction of $\alpha$-bromo- $\omega$-phenyl-poly $(9,9$-dioctylfluorene)with an excess of 4-formylphenylboronic acid, now using the well-known toluene-soda two-phase system, yielded almost quantitatively $\alpha$-(4-formylphenyl)- $\omega$ (phenyl)-poly(2,7-(9,9-dioctylfluorene)). It was then reacted with 2-bromoisobutyl bromide to obtain the polyfluorene macroinitiator, $\alpha$-\{4-[2-(2-bromo-2-methylpropoyloxy)methyl]phenyl $\}$ - $\omega$-bromo-poly[2,7-(9,9-dihexyl-fluorene)] (PF$\mathrm{Br})$. GPC analysis revealed an $\mathrm{Mn}$ of $5300 \mathrm{~g} / \mathrm{mol}$, which corresponds to ten fluorene repeating units. Finally, poly $[2,7-$ (9,9-dihexylfluorene)]-block-poly(2-Vinylpyridine) (PF-b$\mathrm{P} 2 \mathrm{VP}$ ) was synthesized from $\mathrm{PF}-\mathrm{Br}$ by atom transfer radical polymerization. Taking $\mathrm{PF}_{10}-\mathrm{b}-\mathrm{P} 2 \mathrm{VP}_{75}$ as an example, $300 \mathrm{mg}$ ( $1 \mathrm{mmol})$ of $\mathrm{PF}-\mathrm{Br}, 13.4 \mathrm{mg}$ of $\mathrm{CuBr}(2 \mathrm{mmol})$, and $1.056 \mathrm{~mL}$ of 2 -VP $(200 \mathrm{mmol})$ were added to a dry roundbottom flask, and the system was maintained under vacuum for $30 \mathrm{~min}$. $0.02 \mathrm{~mL}$ solution of PMDETA ( $2 \mathrm{mmol}$ ) in $2.6 \mathrm{~mL}$ of THF was added into the round-bottom flask under a nitrogen atmosphere. The mixture was degassed three times, filled with nitrogen, stirred at ambient temperature for $30 \mathrm{~min}$, and immersed into an oil bath at $120^{\circ} \mathrm{C}$ for $24 \mathrm{~h}$. After cooling to room temperature, the mixture was passed through an $\mathrm{Al}_{2} \mathrm{O}_{3}$ column to remove the copper catalyst, precipitated into an excess amount of n-Hexane, filtered off, and the remaining product dried under vacuum at $30^{\circ} \mathrm{C}$ to obtain $100 \mathrm{mg}$ of PF-b-P2VP as a black solid (yields: 95\%). ${ }^{1} \mathrm{H} \mathrm{NMR}\left(\mathrm{CDCl}_{3}\right)$, P2VP block: $\delta(\mathrm{ppm})=8.5-8.0,7.5-6.0$ (4H, pyridine), 3.78 (1H, CH(pyr)-C(O)), 2.3, 1.8 (3H, back-bone). GPC: $\mathrm{Mn}(\mathrm{PF})=5300, \mathrm{Mn}(\mathrm{P} 2 \mathrm{VP})=10700, \mathrm{PDI}=1.33$ for $\mathrm{PF}_{10}$-b-P2VP $35 ; \mathrm{Mn}(\mathrm{PF})=5300, \mathrm{Mn}(\mathrm{P} 2 \mathrm{VP})=11198, \mathrm{PDI}$ $=1.41$ for $\mathrm{PF}_{10}-\mathrm{b}-\mathrm{P} 2 \mathrm{VP}_{55} ; \mathrm{Mn}(\mathrm{PF})=5300, \mathrm{Mn}(\mathrm{P} 2 \mathrm{VP})=$ 14900 , PDI $=1.26$ for $\mathrm{PF}_{10}-\mathrm{b}-\mathrm{P}_{2} \mathrm{VP}_{75}$. Moreover, the prepared PF-b-P2VP copolymer solid was dissolved into the mixed $\mathrm{MeOH} / \mathrm{THF}$ solvents with different volume ratios of $\mathrm{MeOH} / \mathrm{THF}$, that is, $0,10,25,50,75$, and 90\%. During the experiment, it was found that the block chain length of copolymers dominated the morphologies of copolymer aggregates under a fixed copolymer concentration. The effect of polymer concentration could be neglected. Therefore, the polymer concentration of all solution was maintained at $0.1 \mathrm{wt} \%$.

2.3. Characterization. ${ }^{1} \mathrm{H}-\mathrm{NMR}$ spectra of the prepared polymers were performed by a Jeol EX-400 spectrometer. The molecular weight was determined using a GPC instrument equipped with a refractive index detector (Schambeck SFD GmbH, model RI 2000), a Lab Alliance solvent delivery system, and a GPC column (PLgel $5 \mu \mathrm{m}$ mixed, C and D). Calibration was achieved by injecting polystyrene standard diluted to $0.5 \mathrm{wt} \%$ in $\mathrm{THF}(1 \mathrm{~mL} / \mathrm{min})$ at $40^{\circ} \mathrm{C}$. Thermal analyses were carried out on a differential scanning calorimetry (DSC) from TA instruments (TA Q20) with a heating cycle from room temperature to $200^{\circ} \mathrm{C}$ at a heating rate of $20^{\circ} \mathrm{C} / \mathrm{min}$ and a thermal gravimetric analyzer (TGA) from TA instruments 


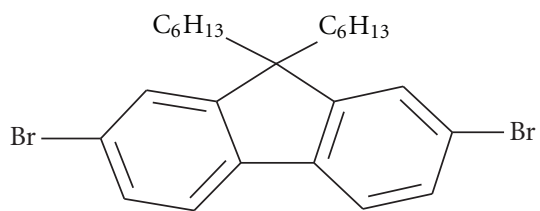

Ethyl ether $\underbrace{\mathrm{B}(\mathrm{OiPr})_{3}}_{n \text {-BuLi }}$

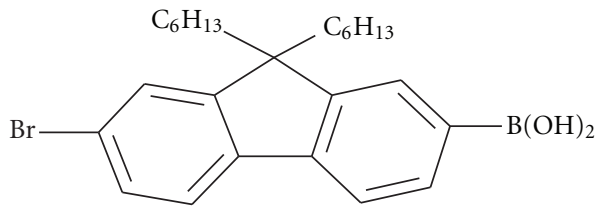

$$
\mathrm{Na}_{2} \mathrm{CO}_{3} \downarrow \begin{gathered}
\mathrm{Pd}\left(\mathrm{PPh}_{3}\right)_{4} \\
\mathrm{DMAc}
\end{gathered}
$$

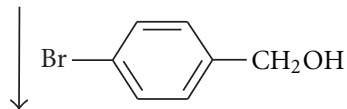

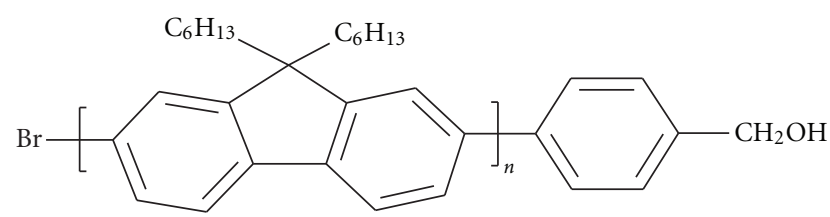
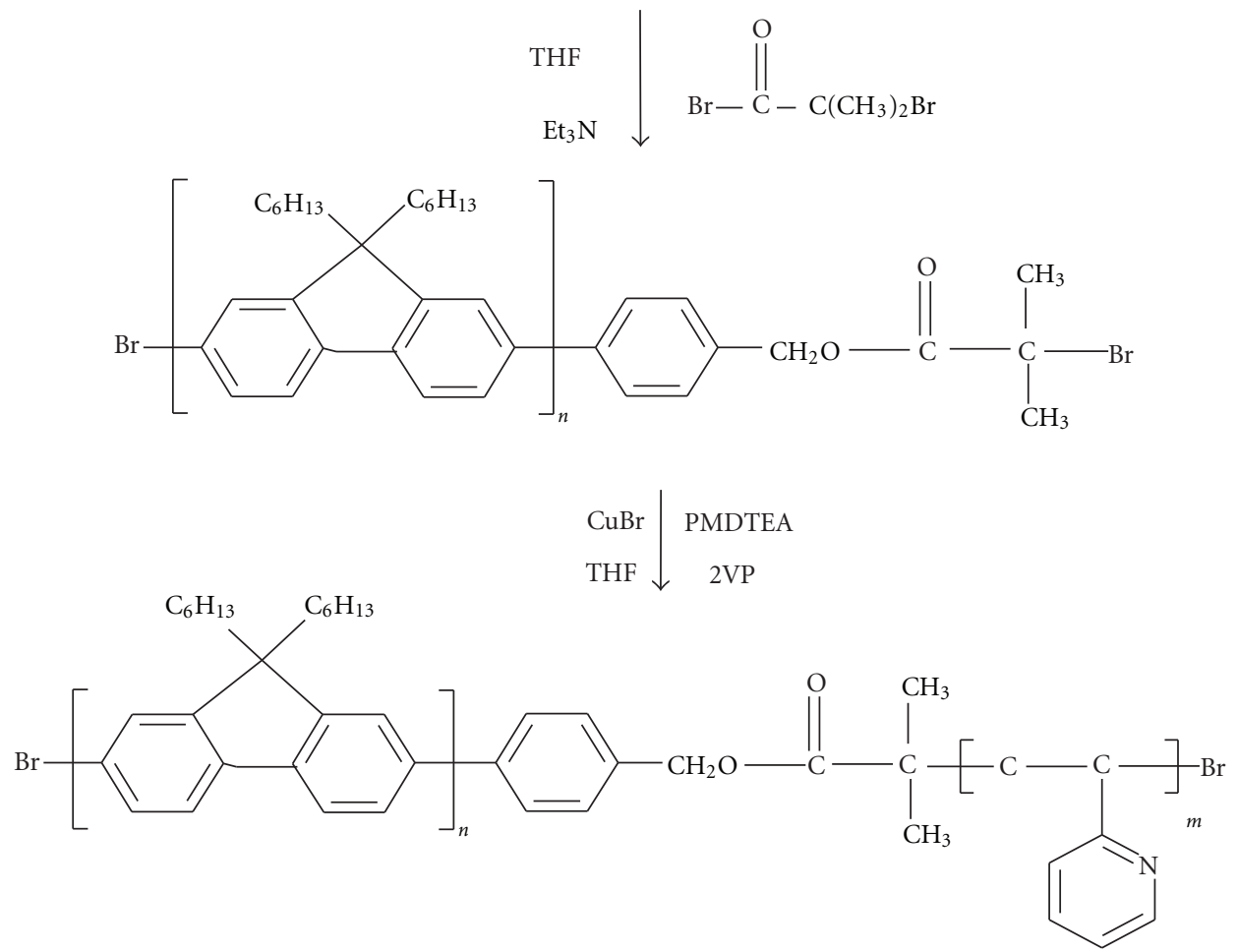

Scheme 1: Chemical structures of the synthesized PF-b-P2VP rod-coil diblock copolymers. 
(TA Q50) with a heating range from room temperature to $900^{\circ} \mathrm{C}$ at a heating rate of $20^{\circ} \mathrm{C} / \mathrm{min}$.

The PF-b-P2VP aggregate morphologies were characterized by transmission electron microscopy (TEM) using a JEOL 1210 operating at an acceleration voltage of $100 \mathrm{kV}$. A drop of the aggregate dispersion was cast onto a 200 mesh copper TEM grid deposited with carbon and dried under vacuum before imaging. The deuterated solvent used for obtaining the spectra was chloroform-d. The AFM data was performed in tapping mode on a Nanoscope DI III multimode AFM. The UV-vis spectra were obtained from polymer thin films prepared on glass by spin coating at a speed of about $1000 \mathrm{rpm}$ using a Jasco Model V-650 spectrometer. The PL spectra were obtained using a Horiba Jobin Yvon Fluoromax4 Spectrofluorometer with a $450 \mathrm{~nm}$ excitation wavelength.

\section{Results and Discussion}

3.1. Micellar Morphologies. In this study, transmission electron microscopy (TEM) and atomic force microscopy (AFM) are utilized for a more detailed investigation of the morphologies for PF-b-P2VP copolymer in solutions and films, respectively, although dynamic light scattering (DLS) has been applied in the investigation of micellar morphology. However, it is known that DLS is not the appropriate tool to use for gaining deeper information on the morphology of micelles [39]. It is because the analytical result of DLS is obviously affected by the operating condition and calculation method. Besides, DLS cannot provide the real morphologies of micellar aggregation. The selectivity of solvents can be manipulated by selecting solvents with various solubility parameters. The solubility of $\mathrm{PF}$ and $\mathrm{P} 2 \mathrm{VP}$ is in the range of 18.62-19.02 $\mathrm{MPa}^{0.5}$ and $27.6 \mathrm{MPa}^{0.5}$, respectively. The solubility of THF and $\mathrm{MeOH}$ is 18.6 and $29.7 \mathrm{MPa}^{0.5}$, respectively. Thus, THF is a suitable solvent for PF and a selective solvent for P2VP. By contrast, methanol is a suitable solvent for P2VP and a selective solvent for PF. Figures $1(\mathrm{a})-1(\mathrm{~d})$ indicate the aggregation behavior of amphiphilic $\mathrm{PF}_{10}-\mathrm{b}-\mathrm{P} 2 \mathrm{VP}_{35}$ in a mixed solution of $\mathrm{MeOH} / \mathrm{THF}$ with various methanol contents: $0,25,50$, and 75 vol.\%. Spherical micelles with a diameter ranging from $50-80 \mathrm{~nm}$ were observed in pure THF solution. This is because THF acts as a good solvent for PF, but as a poor solvent for P2VP, resulting in a spherical morphology with a core of P2VP and a corona of PF. By increasing the methanol content to $10 \mathrm{vol} . \%$, some of the spherical micelles began aggregating with one another to form short worm-like structures less than $500 \mathrm{~nm}$ in length. Increasing the $\mathrm{MeOH}$ content to $25 \mathrm{vol} \%$ resulted in short wormlike structures aggregating to form long three-dimensional network structures, several micrometers in length, due to the ability of these structures to efficiently reduce the interfacial energy of the P2VP core and the PF corona [21]. A further increase in the $\mathrm{MeOH}$ content to $50 \mathrm{vol} . \%$ resulted in the formation of two morphological structures of PF-b-P2VP aggregate: a spherical micelle with a core of $\mathrm{PF}$ and a corona of P2VP and a cylinder with a diameter of 50-100 nm and a length of approximately $300-500 \mathrm{~nm}$. This transformation was due to the expansion of the P2VP core following an increase in $\mathrm{MeOH}$, because $\mathrm{MeOH}$ is a good solvent for P2VP, and the increased selectivity enhances the $\pi-\pi$ stacking of the PF segment, resulting in a cylindrical morphology [22]. When the $\mathrm{MeOH}$ content exceeded $75 \mathrm{vol} \%$, all aggregates of PF-b-P2VP formed spherical micelles with a core of PF and a corona of $\mathrm{P} 2 \mathrm{VP}$, because the mixed solution containing a large proportion of $\mathrm{MeOH}$ facilitated the stretching of hydrophilic P2VP and the aggregation of the hydrophobic $\mathrm{PF}$. Thus, the P2VP core and PF corona prefer to invert to a $\mathrm{PF}$ core and $\mathrm{P} 2 \mathrm{VP}$ corona in the presence of large quantities of $\mathrm{MeOH}$ [21]. The diameter of the phase-inversed spherical aggregate comprising a PF core and $\mathrm{P} 2 \mathrm{VP}$ corona was in the range of 50-80 nm. When the ratio of $\mathrm{MeOH} / \mathrm{THF}$ increased to $90 \mathrm{vol} . \%$, further aggregation between the small micelles occurred to produce larger spherical aggregates up to $200 \mathrm{~nm}$ in diameter, exceeding the size of aggregates comprising a $\mathrm{P} 2 \mathrm{VP}$ core and PF corona. This increase in the size of micelles results from the P2VP chain being longer than the PF chain. Figures 1(e) and 1(f) show AFM images of the topography of $\mathrm{PF}_{10}-\mathrm{P} 2 \mathrm{VP}_{35}$ thin films prepared from mixed solutions of $\mathrm{MeOH} / \mathrm{THF}$ with $25 \mathrm{vol} . \%$ and $50 \mathrm{vol} . \% \mathrm{MeOH}$, respectively. The images also illustrate the morphologies described previously, in agreement with those obtained from TEM.

As the length of hydrophilic P2VP coils increased from $35-55 \mathrm{~nm}$, a similar morphological transformation was observed. Figures 2(a)-2(d) show TEM images of $\mathrm{PF}_{10^{-}}$ b-P2 $\mathrm{VP}_{55}$ in a mixed solution of $\mathrm{MeOH} / \mathrm{THF}$. Aggregates of $\mathrm{PF}_{10}-\mathrm{b}-\mathrm{P} 2 \mathrm{VP}_{55}$ exhibited spherical micelles, similar to $\mathrm{PF}_{10}-\mathrm{b}-\mathrm{P} 2 \mathrm{VP}_{35}$ in pure THF solution. The diameter of the micelles was approximately $70-130 \mathrm{~nm}$, exceeding that of $\mathrm{PF}_{10}-\mathrm{b}-\mathrm{P} 2 \mathrm{VP}_{35}$ owing to the longer $\mathrm{P} 2 \mathrm{VP}$ chain. With an increase in $\mathrm{MeOH}$ content to $10 \mathrm{vol} . \%$, the size of the micelles increased, due to the stretching of the long P2VP chains. The diameter of $\mathrm{PF}_{10}-\mathrm{b}-\mathrm{P}_{2} \mathrm{VP}_{55}$ ranged from $100-150 \mathrm{~nm}$. Although the PF chains shrank with an increase in $\mathrm{MeOH}$ content, P2VP possesses a longer chain than PF; therefore, the volume of P2VP chains increased more than that of PF chains. Although the $\mathrm{MeOH}$ content increased to $25 \mathrm{vol} . \%$, large compound micelles (LCMs) with a diameter of 300-500 nm were observed. The formation of LCMs probably arises from the interpenetration of PF into P2VP. An increase in the $\mathrm{MeOH}$ content to $50 \%$ resulted in the occurrence of phaseinverted micelles with a PF core and P2VP corona, the diameter of which was 50-80 nm. A worm-like morphology was observed with $\mathrm{MeOH}$ contents of 75 and 90 vol.\% because the aggregation of worm-like micelles reduces the stretching of P2VP, leading to a decreased entropy loss [22]. Figures 2(e) and 2(f) show AFM images of the topography of $\mathrm{PF}_{10}-\mathrm{P}_{2} \mathrm{VP}_{55}$ thin films prepared from mixed solutions of $\mathrm{MeOH} / \mathrm{THF}$ with 25 and 50 vol.\% MeOH, respectively. The images exhibit the morphologies described by the TEM analysis.

Figures 3(a)-3(d) show TEM images of $\mathrm{PF}_{10}-\mathrm{b}-\mathrm{P} 2 \mathrm{VP}_{75}$ in mixed solvents of $\mathrm{MeOH} / \mathrm{THF}$, in which the longer $\mathrm{P} 2 \mathrm{VP}$ chains in $\mathrm{PF}_{10}-\mathrm{b}-\mathrm{P} 2 \mathrm{VP}_{75}$ provide a stronger driving force to form a long cylindrical morphology, leading to the coexistence of spherical and short worm-like micelle aggregates in the pure THF solution. The diameters of the spherical and worm-like micelles were $120-180 \mathrm{~nm}$ and $180-250 \mathrm{~nm}$, respectively. With an increase in $\mathrm{MeOH}$ content to $10 \mathrm{vol} . \%$ and $25 \mathrm{vol} . \%$, the size of the worm-like micelles 


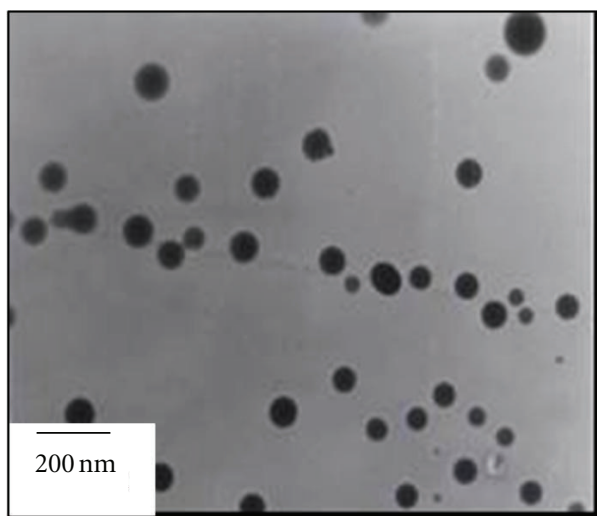

(a)

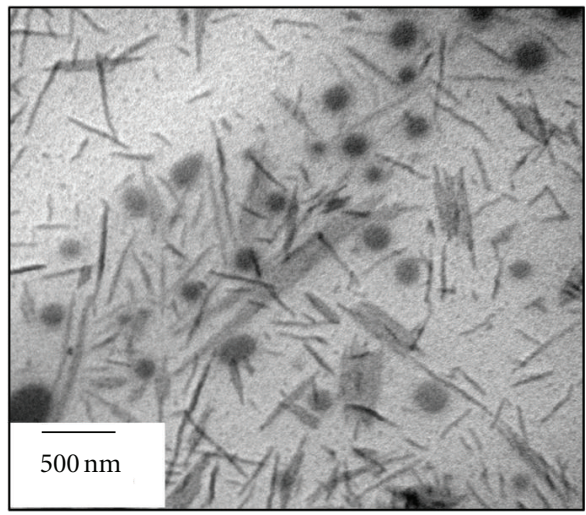

(c)

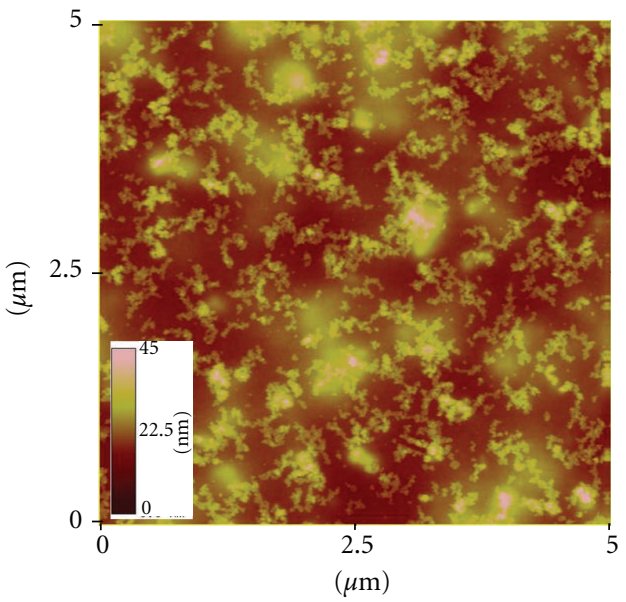

(e)

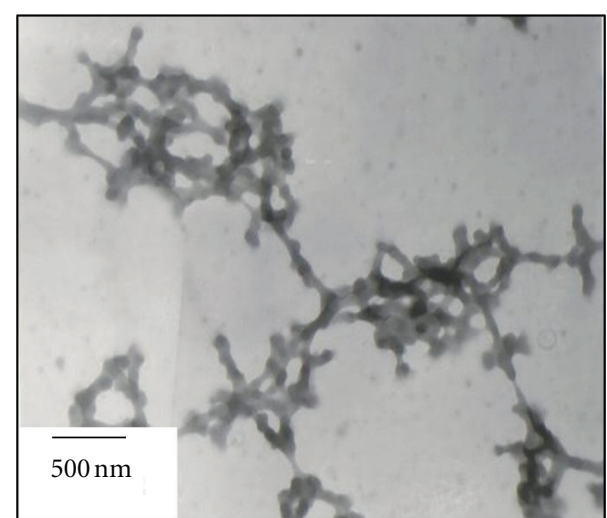

(b)

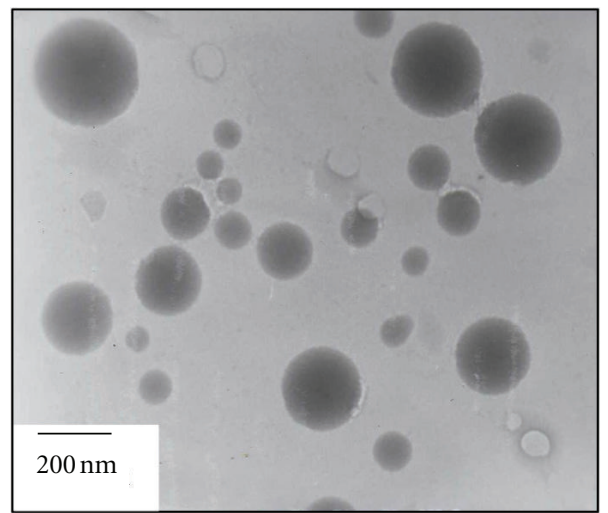

(d)

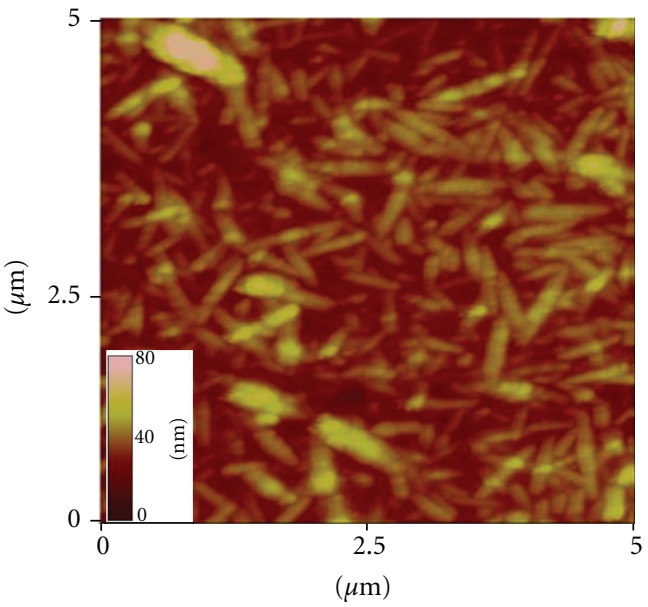

(f)

FIGURE 1: TEM images of $(\mathrm{PF})_{10}$-b-(P2VP) 35 aggregates in dilute solution of MeOH/THF with methanol contents of (a) 0, (b) 25, (c) 50, and (d) 75 vol.\%. (e) and(f) show the AFM images for the thin films of $\mathrm{PF}_{10}-\mathrm{P}_{2} \mathrm{VP}_{35}$ prepared at 25 and 50 vol.\% MeOH content, respectively.

extended to several micrometers. Increasing the $\mathrm{MeOH}$ content to $50 \mathrm{vol} . \%$ resulted in the transformation of the wormlike structures into long cylindrical structures with phaseinverted micelles comprising a PF core and P2VP corona. The length of the cylindrical structures was about several to ten micrometers. As the methanol content was increased to 75 vol.\%; all aggregates of PF-b-P2VP formed phase-inverted spherical micelles with a core of PF, a corona of P2VP, and a diameter of approximately 100-150 nm. With a methanol content of $90 \mathrm{vol} . \%$, the swelling of P2VP increased, due to an increase in the solubility of P2VP, resulting in welldispersed spherical micelles, which increased in size from 150-250 nm. Figures 3(e) and 3(f) show AFM images of the topography of $\mathrm{PF}_{10}-\mathrm{P} 2 \mathrm{VP}_{55}$ thin films prepared from mixed solutions of $\mathrm{MeOH} / \mathrm{THF}$ with $\mathrm{MeOH}$ content of $50 \mathrm{vol} . \%$ and 75 vol.\%, respectively. The images also exhibit the long 


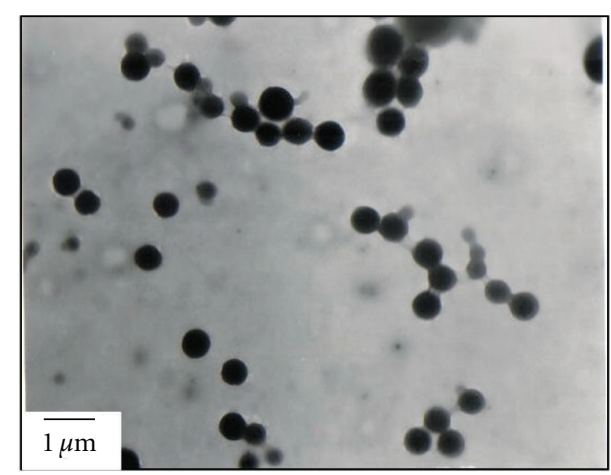

(a)

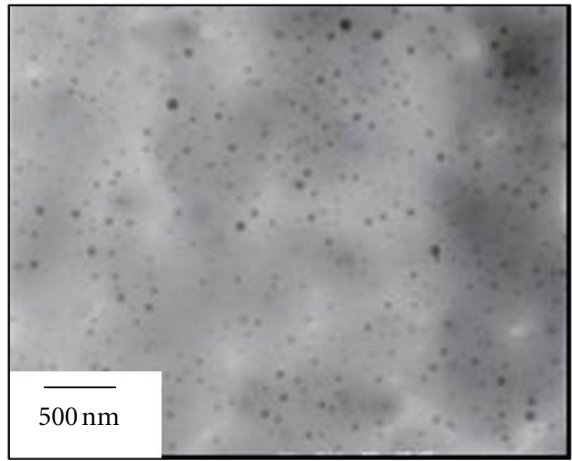

(c)

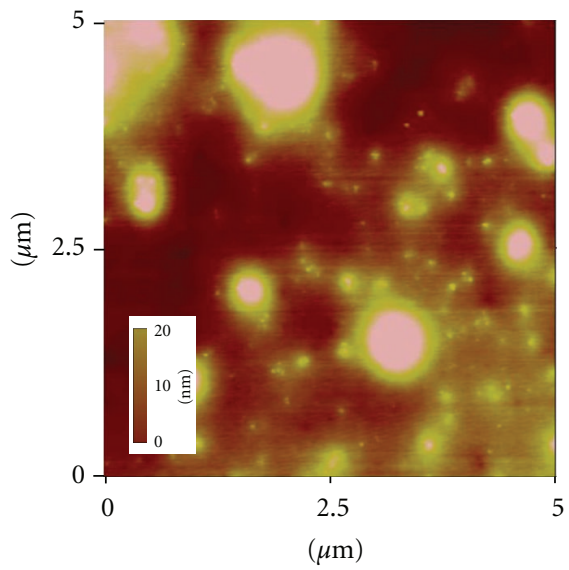

(e)

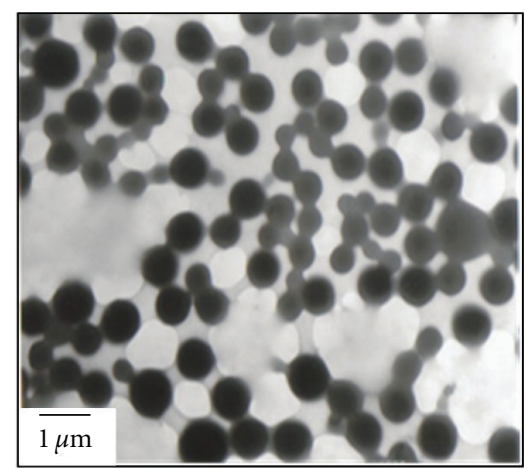

(b)

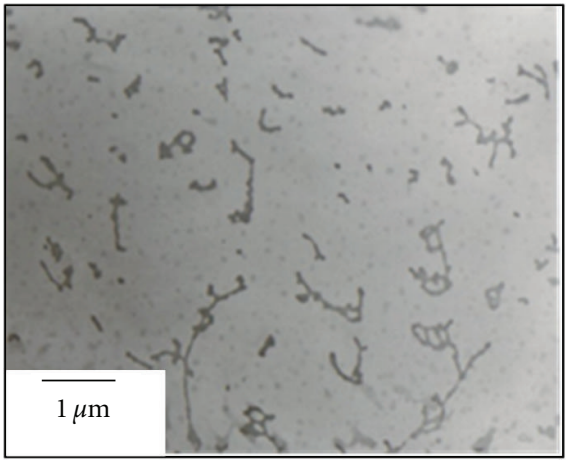

(d)

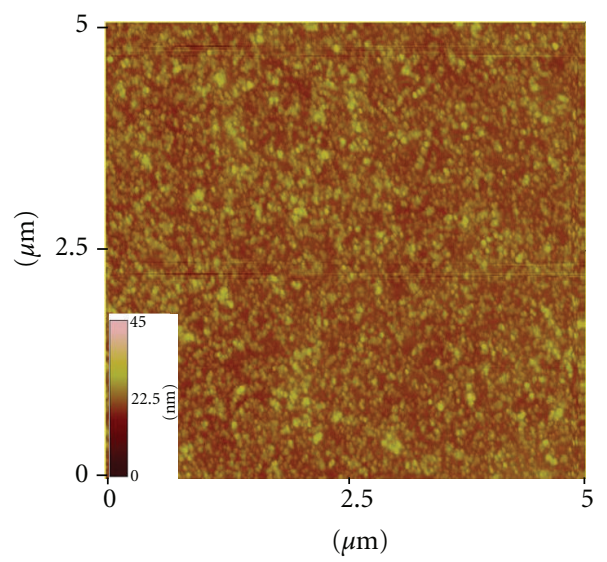

(f)

FIGURE 2: TEM images of $(\mathrm{PF})_{10}$-b-(P2VP) 55 aggregates in dilute solution of MeOH/THF with methanol contents of (a) 0, (b) 25, (c) 50, and (d) 75 vol.\%. (e) and(f) show the AFM images for the thin films of $\mathrm{PF}_{10}-\mathrm{P}_{2} \mathrm{VP}_{55}$ prepared at 25 and 50 vol.\% MeOH content, respectively.

cylindrical and spherical aggregates described previously.

3.2. Photophysical Properties. Figure 4 shows the optical absorption and photoluminescence (PL) spectra of $\mathrm{PF}_{10^{-}}$ $\mathrm{P}_{2} \mathrm{VP}_{75}$ in a dilute solution of $\mathrm{MeOH} / \mathrm{THF}$ with $\mathrm{MeOH}$ content ranging from 0 to $90 \mathrm{vol} . \%$. The photophysical properties of $\mathrm{PF}_{10}-\mathrm{P}_{2} \mathrm{VP}_{35}, \mathrm{PF}_{10}-\mathrm{P}_{2} \mathrm{VP}_{55}$, and $\mathrm{PF}_{10}-\mathrm{P}_{2} \mathrm{VP}_{75}$ are summarized in Table 1. Photophysical analysis shows that both the maximum absorption and photoluminescence spectra of $\mathrm{PF}_{10}-\mathrm{P}_{2} \mathrm{VP}_{35}, \mathrm{PF}_{10}-\mathrm{P}_{2} \mathrm{VP}_{55}$, and $\mathrm{PF}_{10}-\mathrm{P}_{2} \mathrm{VP}_{75}$ thin films exhibit a hypsochromic shift with an increase in $\mathrm{MeOH}$ from $0-90$ vol.\%. The hypsochromic shift is probably due to the fact that the aggregation induced by the poor solvent results in PF segments of reduced coplanarity, leading to a reduction in effective conjugation length [21]. In general, the hypsochromic shift of the absorption spectra is attributed to $\mathrm{H}$-type aggregation, in which conjugation segments are oriented in a parallel direction [22], as shown in Scheme 2. Htype aggregation leads to a blue shift in the absorption spectra and a quenching of fluorescence. The maximum UV-vis peaks of $\mathrm{PF}_{10}-\mathrm{P}_{2} \mathrm{VP}_{35}, \mathrm{PF}_{10}-\mathrm{P}_{2} \mathrm{VP}_{55}$, and $\mathrm{PF}_{10}-\mathrm{P}_{2} \mathrm{VP}_{75}$ shifted from $374 \mathrm{~nm}$ in pure THF solvent to 362,362 , and $356 \mathrm{~nm}$, respectively, in 90 vol.\% MeOH. A similar hypsochromic shift was 


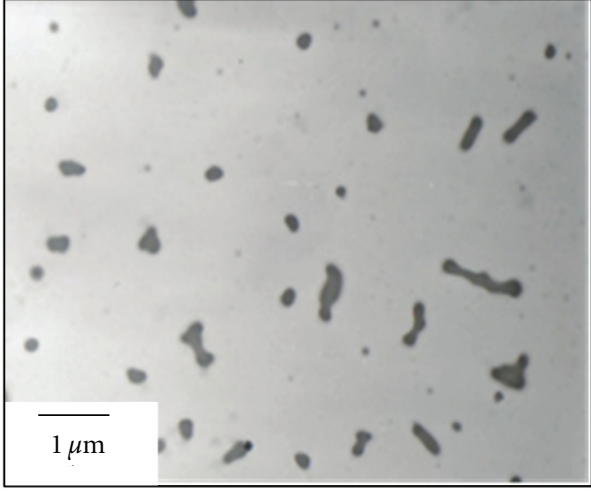

(a)

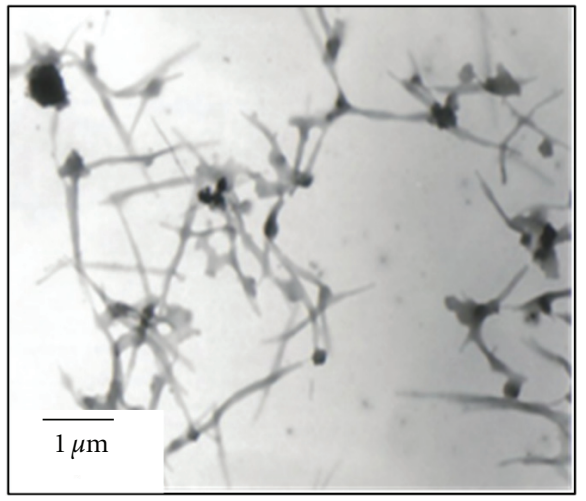

(c)

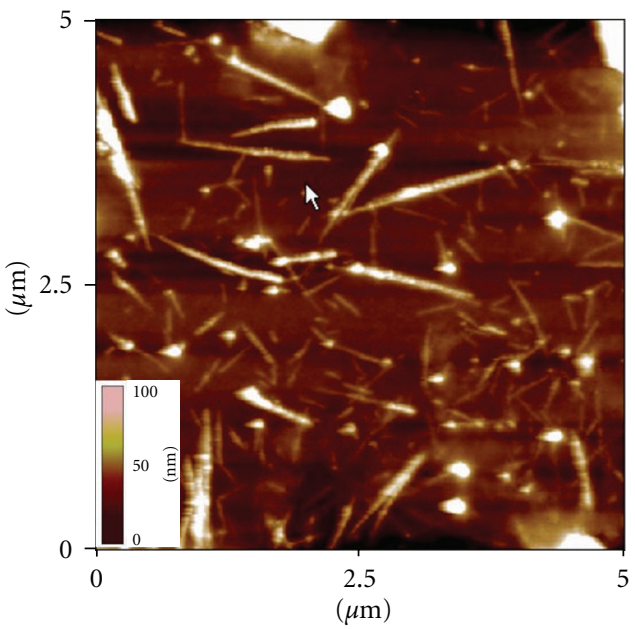

(e)

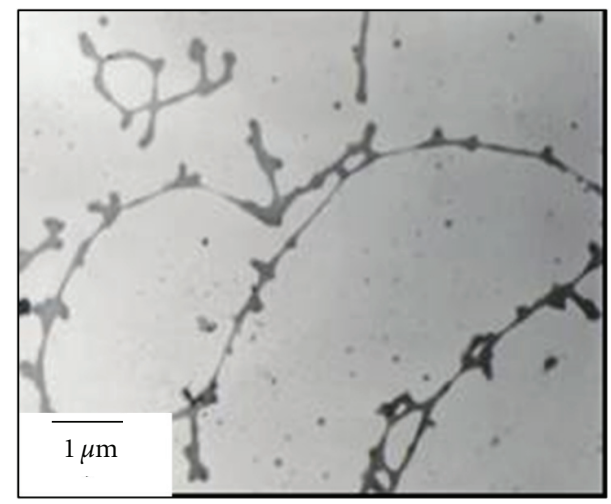

(b)

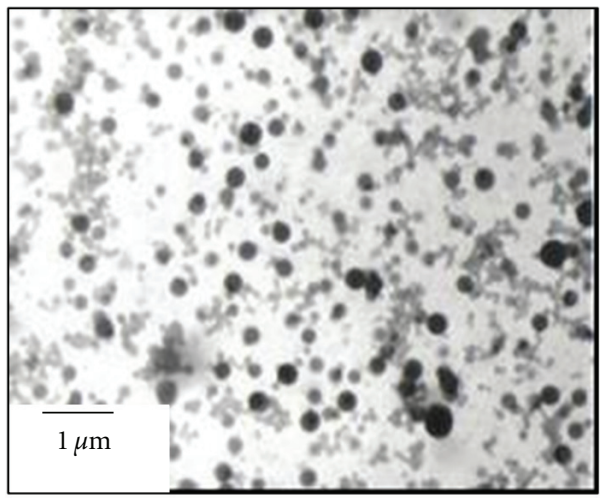

(d)

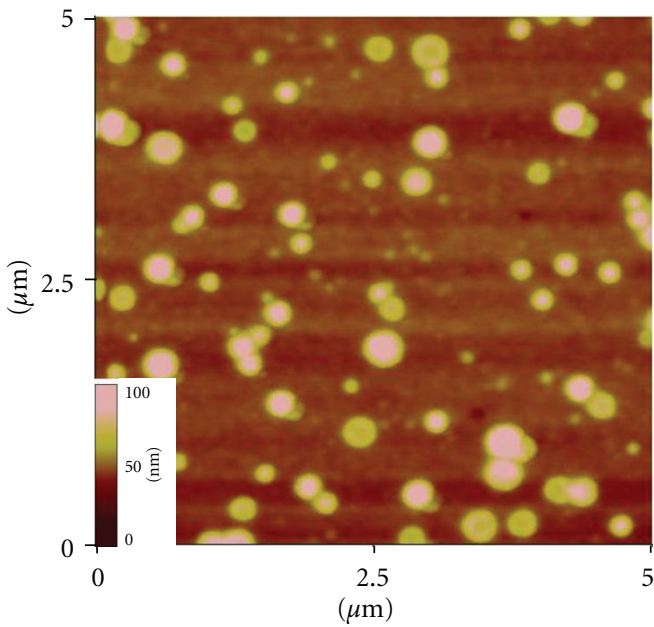

(f)

Figure 3: TEM images of $(\mathrm{PF})_{10}$-b-(P2VP) $)_{75}$ aggregates in dilute solution of MeOH/THF with methanol contents of (a) 0,(b) 25,(c) 50, and (d) 75 vol.\%. (e) and (f) show the AFM images for the thin films of $\mathrm{PF}_{10}-\mathrm{P}_{2} \mathrm{VP}_{75}$ prepared at 50 and 75 vol. $\%$ MeOH content, respectively.

observed in the PL spectra of $\mathrm{PF}_{10}-\mathrm{P} 2 \mathrm{VP}_{75}$ with two emission peaks attributed to the radiative decay of singlet excitons. The maximum $\mathrm{PL}$ peaks of $\mathrm{PF}_{10}-\mathrm{P}_{2} \mathrm{VP}_{35}, \mathrm{PF}_{10}-\mathrm{P}_{2} \mathrm{VP}_{55}$, and $\mathrm{PF}_{10}-\mathrm{P}_{2} \mathrm{VP}_{75}$ shifted from $416 \mathrm{~nm}, 416 \mathrm{~nm}$, and $415 \mathrm{~nm}$ in pure THF solution to 412,410 , and $408 \mathrm{~nm}$, respectively, in 90 vol. $\% \mathrm{MeOH}$. Moreover, the PL quantum yields of $\mathrm{PF}_{10^{-}}$ $\mathrm{P} 2 \mathrm{VP}_{35}, \mathrm{PF}_{10}-\mathrm{P} 2 \mathrm{VP}_{55}$, and $\mathrm{PF}_{10}-\mathrm{P} 2 \mathrm{VP}_{75}$ decreased from 75 ,
72 , and $71 \%$ in pure THF solution to 55,55 , and $45 \%$, respectively, in 90 vol.\% $\mathrm{MeOH}$. The degree of hypsochromic shift and the decrease in PL quantum yield increased as the length of P2VP coils and the content of the poor solvent increased, indicating that photophysical properties can be manipulated by the coil length of the P2VP block and the selectivity of the solvents. 


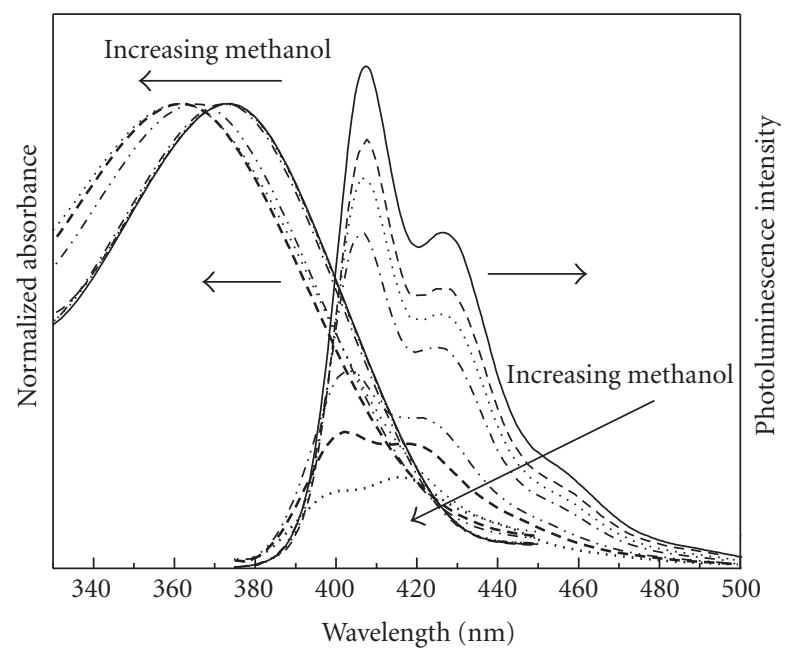

FIGURE 4: Optical absorption and photoluminescence spectra of $(\mathrm{PF})_{10}$-b-(P2VP $)_{75}$ in dilute solution of THF and methanol with methanol contents ranging from 0 to 90 vol.\%.

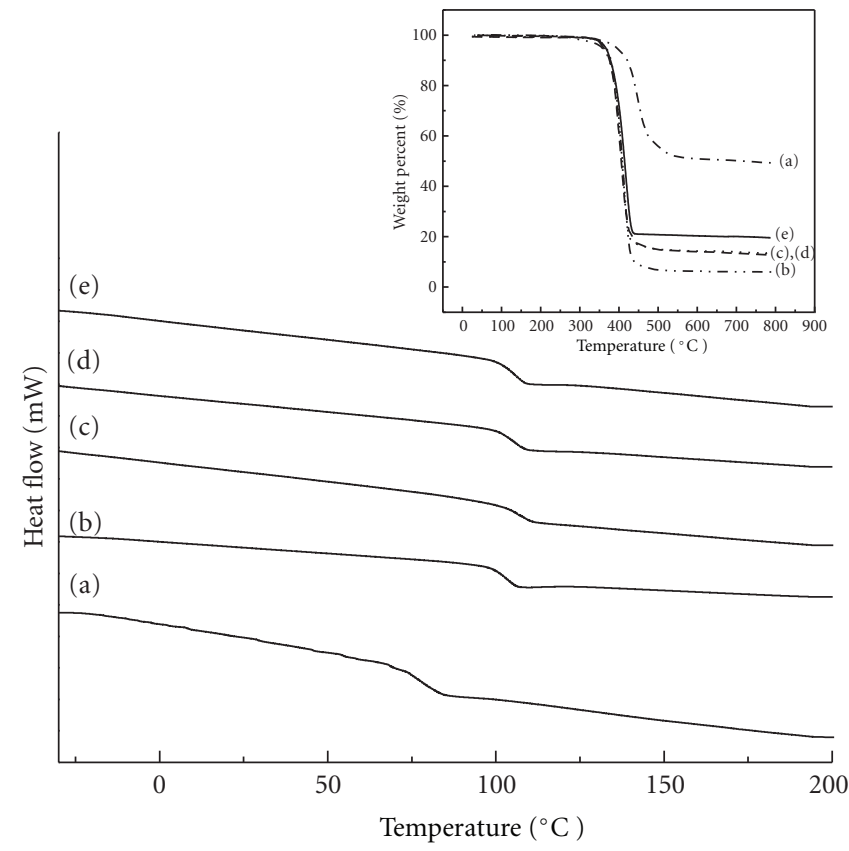

Figure 5: DSC thermograms of (a) PF-vinyl macroinitiator, (b) pure P2VP, (c) $\mathrm{PF}_{10}-\mathrm{b}-\mathrm{P} 2 \mathrm{VP}_{35}$, (d) $\mathrm{PF}_{10}-\mathrm{b}-\mathrm{P} 2 \mathrm{VP}_{55}$, and $(\mathrm{e}) \mathrm{PF}_{10}-\mathrm{b}-\mathrm{P} 2 \mathrm{VP}_{75}$. The inset shows the TGA curves of the previously mentioned corresponding four polymers.

3.3. Effects of Thermal Annealing on Morphology and Photoluminescence. The thermal properties of polymers examined by TGA and DSC are shown in Figure 5. In the inset of Figure 5, the thermal degradation temperature $\left(T_{d}\right)$ (weight loss of 5\%) of (a) PF-vinyl macroinitiator, (b) pure P2VP, (c) $\mathrm{PF}_{10}$-b-P2VP 2 , (d) $\mathrm{PF}_{10}$-b-P2 $\mathrm{VP}_{55}$, and (e) $\mathrm{PF}_{10}$-b-P2 $2 \mathrm{PP}_{75}$ was observed at $394,360,367,363$, and $361^{\circ} \mathrm{C}$, respectively. The glass transition temperatures $\left(T_{g}\right)$ of the previously mentioned five polymers were determined from the DSC curves at $86,109,112,109$, and $109^{\circ} \mathrm{C}$, respectively. The values of $T_{d}$ and $T_{g}$ for the prepared di-block copolymers are close to those of the P2VP homopolymer, because the molecular weight of the P2VP moiety is much greater than that of the PF moiety [22]. Figure 6 shows AFM images of the $\mathrm{PF}_{10}-\mathrm{P}_{2} \mathrm{VP}_{75}$ thin films annealed at room temperature, $80^{\circ} \mathrm{C}, 160^{\circ} \mathrm{C}$, and $240^{\circ} \mathrm{C}$. At room temperature, the morphology of $\mathrm{PF}_{10}-\mathrm{P} 2 \mathrm{VP}_{75}$ exhibited a rough surface. With an increase in annealing temperature, surface roughness decreased, presumably because the thermal energy facilitated the movement of polymer chains, which smoothed the surface at higher temperatures. Figures 7 and 8 show the PL spectra of macroinitiators $\mathrm{PF}-\mathrm{Br}$ and $\mathrm{PF}_{10}-\mathrm{P} 2 \mathrm{VP}_{75}$, respectively, as a function of annealing time at $120^{\circ} \mathrm{C}$. Thin films of $\mathrm{PF}$ macroinitiator and $\mathrm{PF}_{10}-\mathrm{P} 2 \mathrm{VP}_{75}$ were prepared 


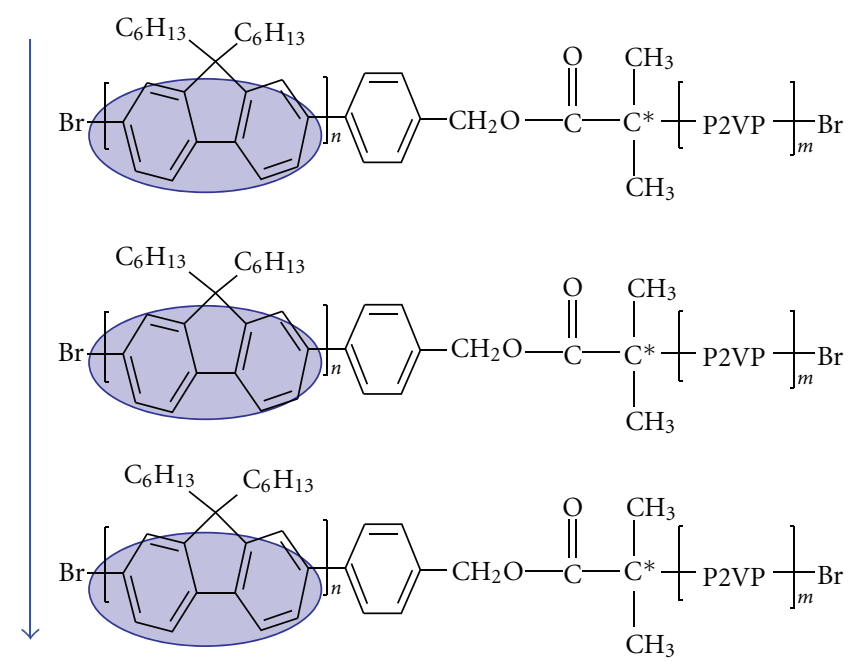

(a) $\mathrm{H}$ type

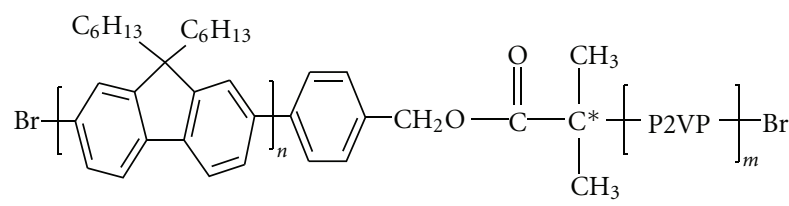

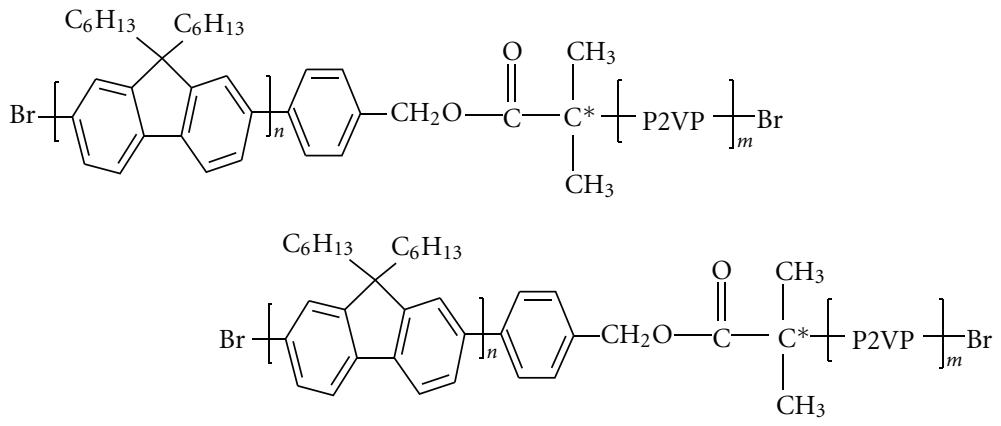

(b) J type

Scheme 2: Schematic illustration of (a) H-type and (b) J-type aggregates of diblock PF-b-P2VP copolymers.

TABLE 1: UV-vis and PL characteristics of $\mathrm{PF}_{10}-\mathrm{b}-\mathrm{P} 2 \mathrm{VP}_{35}, \mathrm{PF}_{10}-\mathrm{b}-\mathrm{P} 2 \mathrm{VP}_{55}$, and $\mathrm{PF}_{10}-\mathrm{b}-\mathrm{P} 2 \mathrm{VP}_{75}$ thin films in the various ratios of $\mathrm{MeOH} / \mathrm{THF}$ solvents.

\begin{tabular}{|c|c|c|c|c|c|c|c|c|c|}
\hline \multirow{2}{*}{$\mathrm{MeOH} / \mathrm{THF}^{1}$} & \multicolumn{3}{|c|}{$\mathrm{PF}_{10}-\mathrm{b}-\mathrm{P} 2 \mathrm{VP}_{35}$} & \multicolumn{3}{|c|}{$\mathrm{PF}_{10}-\mathrm{b}-\mathrm{P} 2 \mathrm{VP}_{55}$} & \multicolumn{3}{|c|}{$\mathrm{PF}_{10}-\mathrm{b}-\mathrm{P} 2 \mathrm{VP}_{75}$} \\
\hline & $\lambda_{\max }^{2}(\mathrm{~nm})$ & $\lambda_{\max }^{3}(\mathrm{~nm})$ & $\psi^{4}(\%)$ & $\lambda_{\max }^{2}(\mathrm{~nm})$ & $\lambda_{\max }^{3}(\mathrm{~nm})$ & $\psi^{4}(\%)$ & $\lambda_{\max }^{2}(\mathrm{~nm})$ & $\lambda_{\max }{ }^{3}(\mathrm{~nm})$ & $\psi^{4}(\%)$ \\
\hline $0 / 100$ & 374 & 416 & 75 & 374 & 416 & 72 & 374 & 415 & 71 \\
\hline $10 / 90$ & 374 & 416 & 68 & 374 & 416 & 65 & 374 & 414 & 64 \\
\hline $25 / 75$ & 374 & 415 & 60 & 372 & 416 & 58 & 374 & 415 & 56 \\
\hline $50 / 50$ & 372 & 414 & 59 & 372 & 415 & 56 & 370 & 413 & 52 \\
\hline $75 / 25$ & 366 & 413 & 57 & 366 & 412 & 55 & 364 & 411 & 48 \\
\hline $90 / 10$ & 362 & 412 & 55 & 362 & 410 & 55 & 356 & 408 & 45 \\
\hline
\end{tabular}

${ }^{1}$ The various volume ratios of $\mathrm{MeOH} / \mathrm{THF}$ solvent.

${ }^{2}$ The maximum peaks of UV-vis spectra.

${ }^{3}$ The maximum peaks of PL spectra.

${ }^{4}$ The quantum yields of PL. 


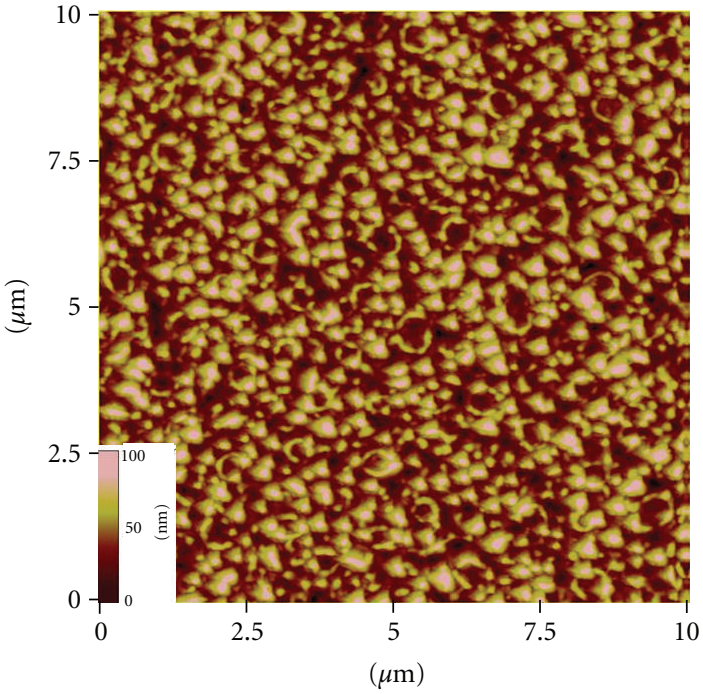

(a)

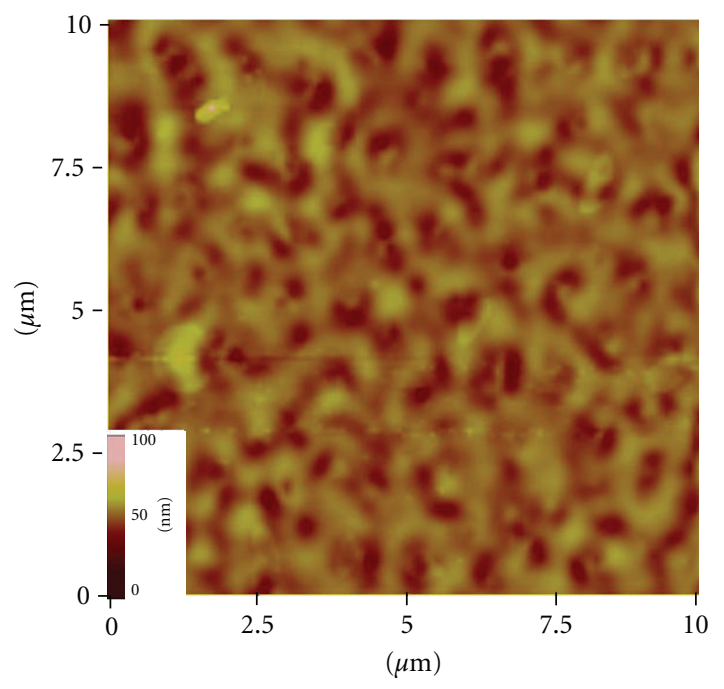

(c)

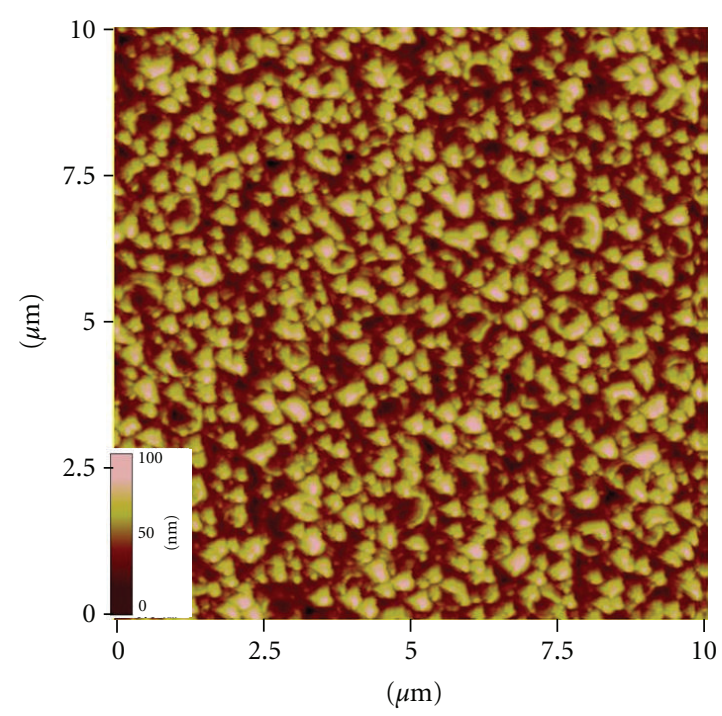

(b)

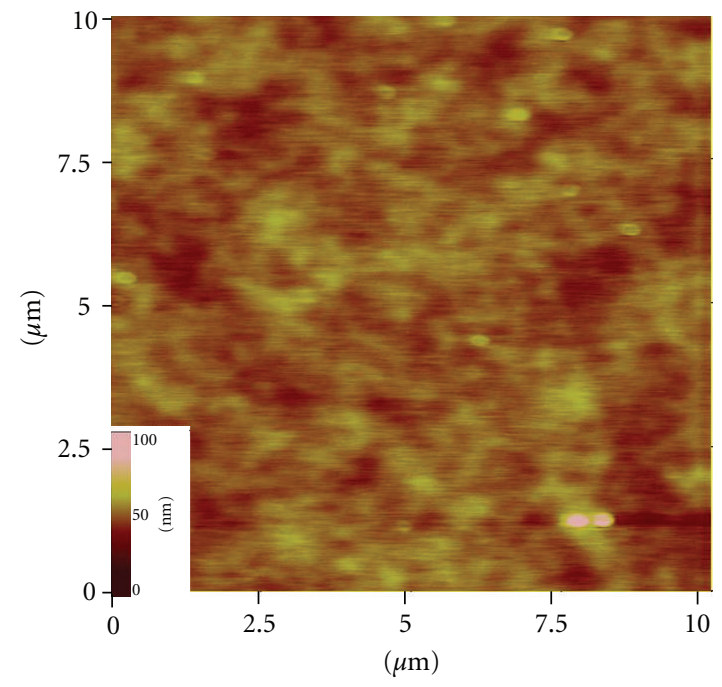

(d)

Figure 6: AFM images of $(\mathrm{PF})_{10}$-b-(P2VP) $)_{75}$ obtained at various heating temperature of (a) room temperature, $(\mathrm{b}) 80^{\circ} \mathrm{C},(\mathrm{c}) 160^{\circ} \mathrm{C}$, and $(\mathrm{d})$ $240^{\circ} \mathrm{C}$, respectively.

by spin coating and annealing at $120^{\circ} \mathrm{C}$ in a convection oven for various durations ranging from 0 to $15 \mathrm{~h}$ prior to the measurement of PL. Both samples were heat-treated under the same experimental conditions. The results show that the $\mathrm{PL}$ emission of $\mathrm{PF}-\mathrm{Br}$ and $\mathrm{PF}_{10}-\mathrm{P}_{2} \mathrm{VP}_{75}$ increases in the range of 500-600 nm with amplified annealing times, indicating the formation of excimers. The emission of PF-Br at $525 \mathrm{~nm}$ is much stronger than that of $\mathrm{PF}_{10}-\mathrm{P}_{2} \mathrm{VP}_{75}$, which means that $\mathrm{PF}_{10}-\mathrm{P} 2 \mathrm{VP}_{75}$ possesses better spectral stability at higher temperatures. The enhanced stability is probably due to the fact that the P2VP coil suppresses the formation of excimers in the PF blocks during annealing at high temperatures [40].

\section{Conclusions}

The synthesis, morphology, and photophysical characterizations of three amphiphilic rod-coil diblock copolymers comprising $\mathrm{PF}$ and $\mathrm{P} 2 \mathrm{VP}$ with coil chains of various lengths have been demonstrated. A range of morphologies, including spherical, cylindrical, worm-like, dendritic, and large-compound micelles, were observed by varying the coil length and selectivity of mixed $\mathrm{MeOH} / \mathrm{THF}$ solvents. These morphologies induce considerable variation in the optical absorption, fluorescence, and PL quantum yields of rodcoil diblock copolymers. The degree of hypsochromic shift and PL quenching are enhanced with an increase in the length of the P2VP coil and the proportion of poor solvent, due to H-type aggregation. This indicates that photophysical properties can be manipulated according to the coil length of the P2VP block and the selectivity of solvents. Furthermore, the P2VP segments efficiently suppress the formation of excimers, indicating that the spectral stability of polyfluorene can be improved through manipulation of the architecture of diblock rod-coil copolymers. This study 


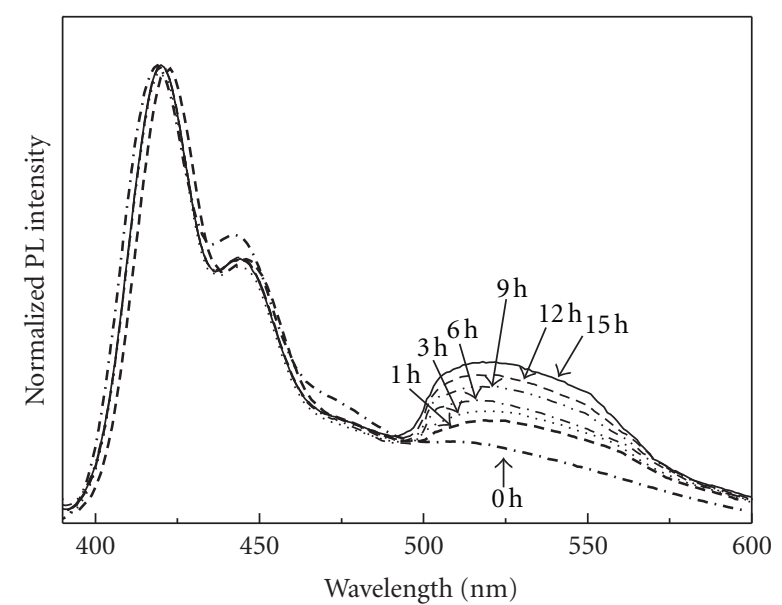

FIGURE 7: Photoluminescence spectra of the thin film of PF macroinitiator annealed at $120^{\circ} \mathrm{C}$ for $0 \mathrm{~h}, 1 \mathrm{~h}, 3 \mathrm{~h}, 6 \mathrm{~h}, 9 \mathrm{~h}, 12 \mathrm{~h}$, and $15 \mathrm{~h}$.

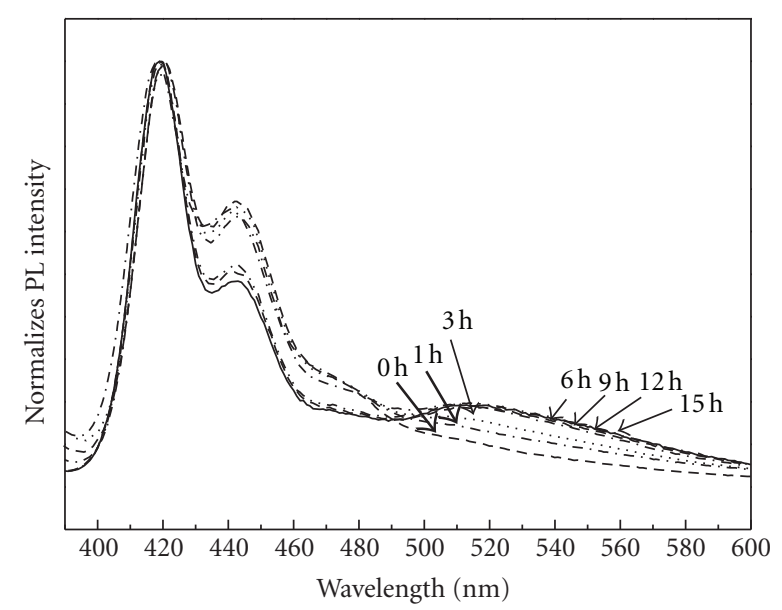

FIGURE 8: Photoluminescence spectra of the thin film of PF macroinitiator, $(\mathrm{PF})_{10}-\mathrm{b}-(\mathrm{P} 2 \mathrm{VP})_{75}$ annealed at $120^{\circ} \mathrm{C}$ for $0 \mathrm{~h}, 1 \mathrm{~h}, 3 \mathrm{~h}$, $6 \mathrm{~h}, 9 \mathrm{~h}, 12 \mathrm{~h}$, and $15 \mathrm{~h}$.

demonstrates the importance of coil length and the selectivity of solvents on the morphology and optical characteristics of rod-coil copolymers. Further, the importance of rod length on the morphology and optical characteristics of rod-coil copolymers will be investigated in our next study.

\section{Acknowledgment}

The authors would like to acknowledge the financial support of the National Science Council through Project NSC 1012221-E-131-006-MY3.

\section{References}

[1] A. Hirao, M. Hayashi, S. Loykulnant et al., "Precise syntheses of chain-multi-functionalized polymers, star-branched polymers, star-linear block polymers, densely branched polymers, and dendritic branched polymers based on iterative approach using functionalized 1,1-diphenylethylene derivatives," Progress in Polymer Science, vol. 30, no. 2, pp. 111-182, 2005.

[2] P. Chen, G. Yang, T. Liu, T. Li, M. Wang, and W. Huang, "Optimization of opto-electronic property and device efficiency of polyfluorenes by tuning structure and morphology," Polymer International, vol. 55, no. 5, pp. 473-490, 2006.

[3] Y. Liang, H. Wang, S. Yuan, Y. Lee, L. Gan, and L. Yu, "Conjugated block copolymers and co-oligomers: from supramolecular assembly to molecular electronics," Journal of Materials Chemistry, vol. 17, no. 21, pp. 2183-2194, 2007.

[4] Y. B. Lim, K. S. Moon, and M. Lee, "Rod-coil block molecules: their aqueous self-assembly and biomaterials applications," Journal of Materials Chemistry, vol. 18, no. 25, pp. 2909-2918, 2008.

[5] X. Yang, F. Yi, Z. Xin, and S. Zheng, "Morphology and mechanical properties of nanostructured blends of epoxy resin with poly( $\varepsilon$-caprolactone)-block-poly(butadiene-co-acrylonitrile)block-poly(e-caprolactone) triblock copolymer," Polymer, vol. 50, no. 16, pp. 4089-4100, 2009.

[6] J. F. Gohy, "Metallo-supramolecular block copolymer micelles," Coordination Chemistry Reviews, vol. 253, no. 17-18, pp. 2214-2225, 2009.

[7] Y. Wang, M. Zhang, C. Moers et al., "Block copolymer aggregates with photo-responsive switches: towards a controllable supramolecular container," Polymer, vol. 50, no. 20, pp. 4821-4828, 2009.

[8] S. W. Kuo, P. H. Tung, and F. C. Chang, "Hydrogen bond mediated supramolecular micellization of diblock copolymer mixture in common solvents," European Polymer Journal, vol. 45, no. 7, pp. 1924-1935, 2009.

[9] J. Tata, D. Scalarone, M. Lazzari, and O. Chiantore, "Control of morphology orientation in thin films of PS-b-PEO diblock copolymers and PS-b-PEO/resorcinol molecular complexes," European Polymer Journal, vol. 45, no. 9, pp. 2520-2528, 2009.

[10] Y. W. Li, H. Li, B. Xu et al., "Molecular structure-property engineering for photovoltaic applications: fluorene-acceptor alternating conjugated copolymers with varied bridged moieties," Polymer, vol. 51, pp. 1786-1795, 2010.

[11] D. Yang, L. Tong, Y. Li, J. Hu, S. Zhang, and X. Huang, "A novel well-defined amphiphilic diblock copolymer containing perfluorocyclobutyl aryl ether-based hydrophobic segment," Polymer, vol. 51, no. 8, pp. 1752-1760, 2010.

[12] A. E. Smith, X. Xu, and C. L. McCormick, "Stimuli-responsive amphiphilic (co)polymers via RAFT polymerization," Progress in Polymer Science, vol. 35, no. 1-2, pp. 45-93, 2010.

[13] C. L. Liu, C. H. Lin, C. C. Kuo, S. T. Lin, and W. C. Chen, "Conjugated rod-coil block copolymers: synthesis, morphology, photophysical properties, and stimuli-responsive applications," Progress in Polymer Science, vol. 36, no. 5, pp. 603-637, 2011.

[14] G. Chang, L. Yu, Z. Yang, and J. Ding, "A delicate ionizablegroup effect on self-assembly and thermogelling of amphiphilic block copolymers in water," Polymer, vol. 50, no. 25, pp. 6111-6120, 2009.

[15] T. Qu, A. Wang, J. Yuan, and Q. Gao, "Preparation of an amphiphilic triblock copolymer with $\mathrm{pH}$ - and thermo-responsiveness and self-assembled micelles applied to drug release," Journal of Colloid and Interface Science, vol. 336, no. 2, pp. 865-871, 2009.

[16] H. J. Chung and T. G. Park, "Self-assembled and nanostructured hydrogels for drug delivery and tissue engineering," Nano Today, vol. 4, no. 5, pp. 429-437, 2009. 
[17] M. Lee, B. K. Cho, and W. C. Zin, "Supramolecular structures from rod-coil block copolymers," Chemical Reviews, vol. 101, no. 12, pp. 3869-3892, 2001.

[18] F. J. M. Hoeben, P. Jonkheijm, E. W. Meijer, and A. P. H. J. Schenning, "About supramolecular assemblies of $\pi$-conjugated systems," Chemical Reviews, vol. 105, no. 4, pp. 1491-1546, 2005.

[19] J. J. L. M. Cornelissen, M. Fischer, N. A. J. M. Sommerdijk, and R. J. M. Nolte, "Helical superstructures from charged poly(styrene)- poly(isocyanodipeptide) block copolymers," Science, vol. 280, no. 5368, pp. 1427-1430, 1998.

[20] S. A. Jenekhe and X. L. Chen, "Self-assembled aggregates of rodcoil block copolymers and their solubilization and encapsulation of fullerenes," Science, vol. 279, no. 5358, pp. 1903-1907, 1998.

[21] Y. C. Tung, W. C. Wu, and W. C. Chen, "Morphological transformation and photophysical properties of rod-coil poly[2,7(9,9- Dihexylfluorene)]-block-poly(acrylic acid) in solution," Macromolecular Rapid Communications, vol. 27, no. 21, pp. 1838-1844, 2006.

[22] C. H. Lin, Y. C. Tung, J. Ruokolainen, R. Mezzenga, and W. C. Chen, "Poly[2,7-(9,9-dihexylfluorene)]-block-poly(2-vinylpyridine) rod-coil and coil-rod-coil block copolymers: synthesis, morphology and photophysical properties in methanol/THF mixed solvents," Macromolecules, vol. 41, no. 22, pp. 8759-8769, 2008.

[23] G. Zhang, D. Wang, and H. Mohwald, "Nanoembossment of Au patterns on microspheres," Materials Chemistry, vol. 18, pp. 3985-3992, 2006.

[24] Y. C. Tung and W. C. Chen, "Poly[2,7-(9,9-dihexylfluorene)]block-poly[3-(trimethoxysilyl)propyl methacrylate] (PF-bPTMSPMA) rod-coil block copolymers: synthesis, morphology and photophysical properties in mixed solvents," Reactive and Functional Polymers, vol. 69, no. 7, pp. 507-518, 2009.

[25] C. A. Dai, W. C. Yen, Y. H. Lee, C. C. Ho, and W. F. Su, "Facile synthesis of well-defined block copolymers containing regioregular poly(3-hexyl thiophene) via anionic macroinitiation method and their self-assembly behavior," Journal of the American Chemical Society, vol. 129, no. 36, pp. 11036-11038, 2007.

[26] C. L. Zhu, L. B. Liu, Q. Yang, F. T. Lv, and S. Wang, "Watersoluble conjugated polymers for imaging, diagnosis, and therapy," Chemical Reviews, vol. 112, pp. 4687-4735, 2012.

[27] A. Kaeser and A. P. Schenning, "Fluorescent nanoparticles based on self-assembled $\pi$-conjugated systems," Advanced Materials, vol. 22, pp. 2985-2997, 2010.

[28] R. Abbel, A. P. H. J. Schenning, and E. W. Meijer, "Fluorenebased materials and their supramolecular properties," Journal of Polymer Science A, vol. 47, no. 17, pp. 4215-4233, 2009.

[29] J. Zaumseil and H. Sirringhaus, "Electron and ambipolar transport in organic field-effect transistors," Chemical Reviews, vol. 107, no. 4, pp. 1296-1323, 2007.

[30] W. C. Wu, W. Y. Lee, and W. C. Chen, "New fluorene-acceptor random copolymers: towards pure white light emission from a single polymer," Macromolecular Chemistry and Physics, vol. 207, no. 13, pp. 1131-1138, 2006.

[31] W. C. Wu, C. L. Liu, and W. C. Chen, "Synthesis and characterization of new fluorene-acceptor alternating and random copolymers for light-emitting applications," Polymer, vol. 47, no. 2, pp. 527-538, 2006.

[32] G. Bernardo, A. Charas, and J. Morgado, "Luminescence properties of poly(9,9-dioctylfluorene)/polyvinylcarbazole blends: role of composition on the emission colour stability and electroluminescence efficiency," Journal of Physics and Chemistry of Solids, vol. 71, no. 3, pp. 340-345, 2010.

[33] Z. S. Guo, J. Pei, Z. L. Zhou et al., "Amine groups-functionalized alcohol-soluble polyfluorene derivatives: synthesis, photophysical properties, and self-assembly behaviors," Polymer, vol. 50, no. 20, pp. 4794-4800, 2009.

[34] Y. K. Kwon, H. S. Kim, H. J. Kim et al., "Reduced excimer formation in polyfluorenes by introducing coil-like poly[penta(ethylene glycol) methyl ether methacrylate] block segments," $M a$ cromolecules, vol. 42, no. 3, pp. 887-891, 2009.

[35] S. Lu, Q. L. Fan, S. J. Chua, and W. Huang, "Synthesis of conjugated-ionic block copolymers by controlled radical polymerization," Macromolecules, vol. 36, no. 2, pp. 304-310, 2003.

[36] C. L. Chochos, P. K. Tsolakis, V. G. Gregoriou, and J. K. Kallitsis, "Influence of the coil block on the properties of rod-coil diblock copolymers with oligofluorene as the rigid segment," Macromolecules, vol. 37, no. 7, pp. 2502-2510, 2004.

[37] S. Lu, T. Liu, L. Ke, D. G. Ma, S. J. Chua, and W. Huang, "Polyfluorene-based light-emitting rod-coil block copolymers," Macromolecules, vol. 38, no. 20, pp. 8494-8502, 2005.

[38] D. Marsitzky, M. Klapper, and K. Müllen, "End-functionalization of poly(2,7-fluorene): a key step toward novel luminescent rod-coil block copolymers," Macromolecules, vol. 32, no. 25, pp. 8685-8688, 1999.

[39] J. F. Gohy, H. Hofmeier, A. Alexeev, and U. S. Schubert, "Aqueous micelles from supramolecular graft copolymers," Macromolecular Chemistry and Physics, vol. 204, pp. 1524-1530, 2003.

[40] Y. K. Kwon, H. S. Kim, H. J. Kim et al., "Reduced excimer formation in polyfluorenes by introducing coil-like poly[penta(ethylene glycol) methyl ether methacrylate] block segments," Macromolecules, vol. 42, no. 3, pp. 887-891, 2009. 

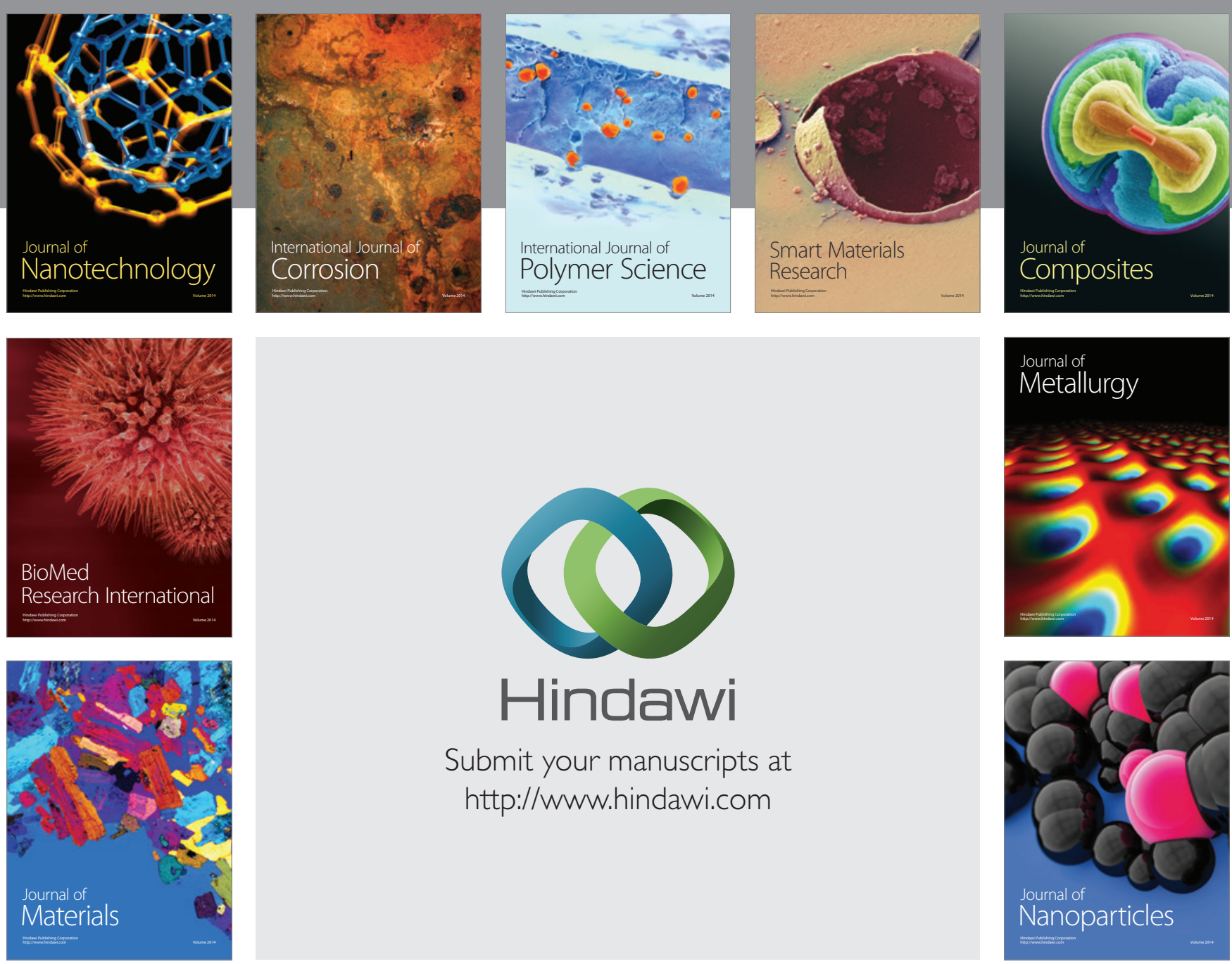

Submit your manuscripts at http://www.hindawi.com
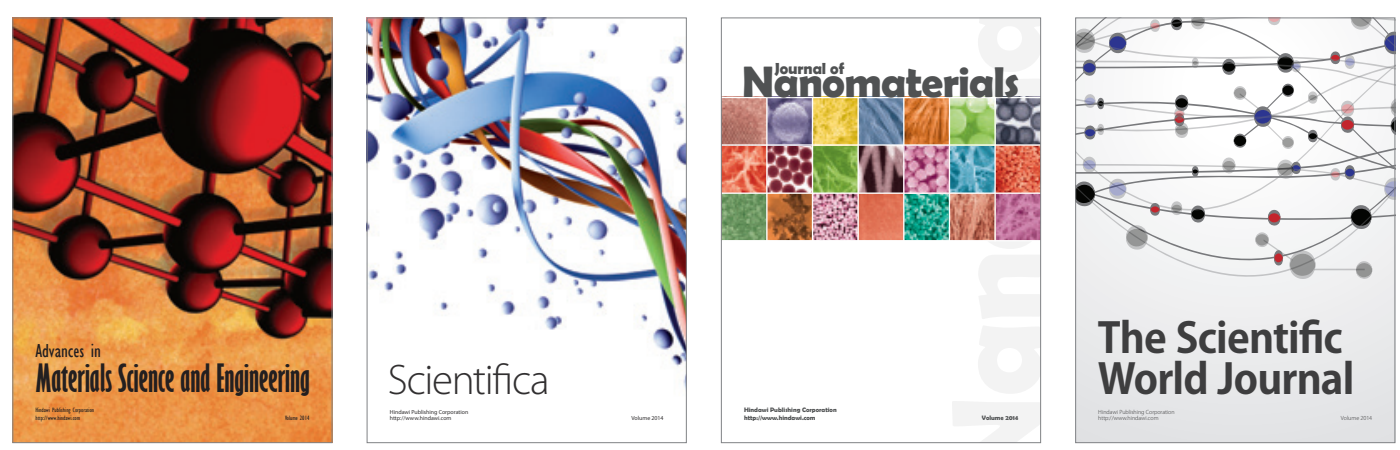

\section{The Scientific World Journal}
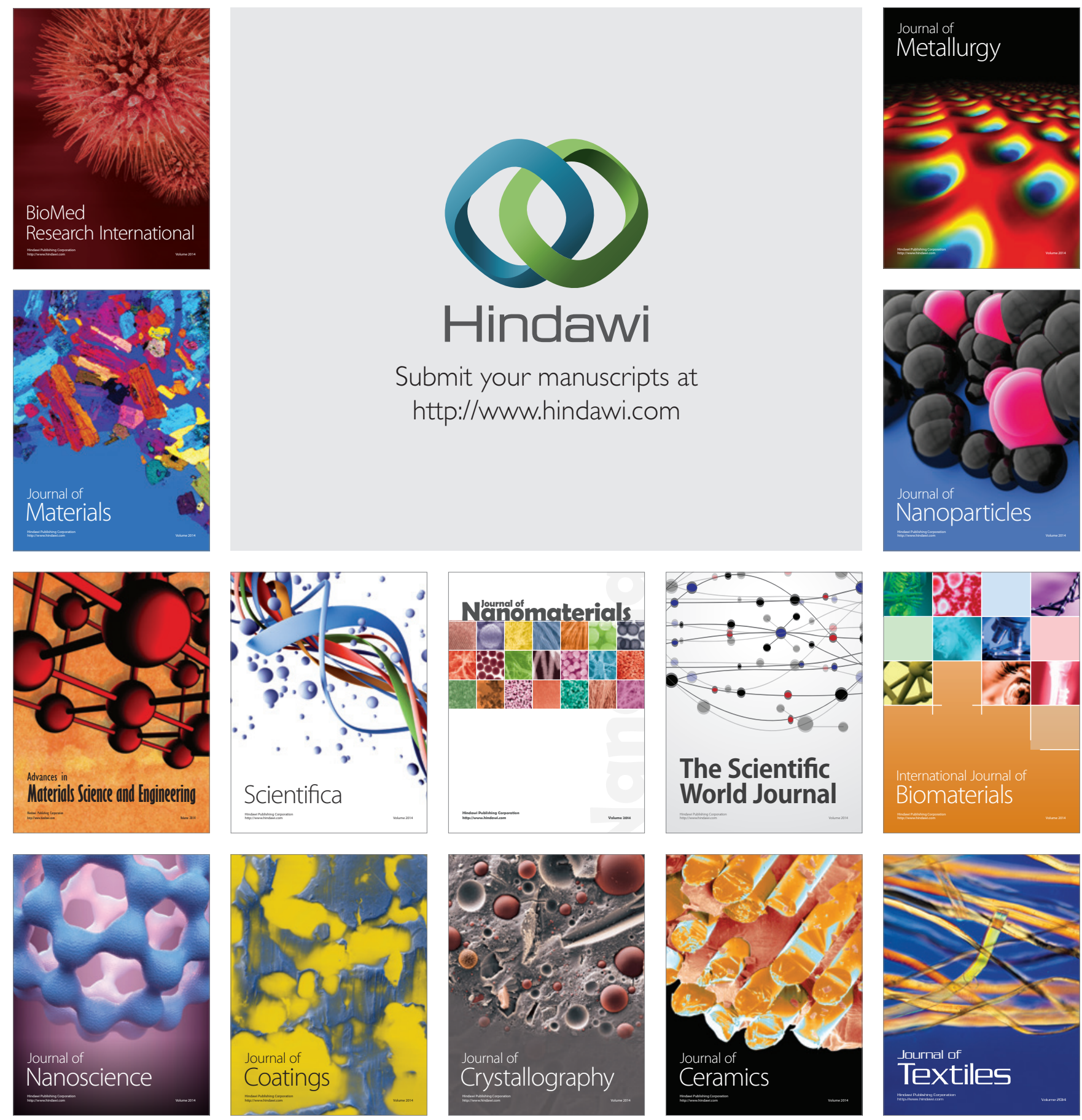